PALABRAS CLAVE I SISMOS • HISTORIA DE LA ARPUITECTURA - DESAMPARO URBANO • ORFANDAD POLITICA • DIMENSIÓN SIMBÓLICA

KEYWORDS I EARTHPUAKES • HISTORY OF ARCHITECTURE BBAN HELPLESSNESS • POLITIC ORPHANAGE • SYMBOLIC DIMENSION

\section{Earthquakes: a history of fragments}

\section{| RESUMEN |}

Los sismos además de todas sus trágicas consecuencias se constituyen en un momento de detención, una pausa que permite la apertura a diversos dominios simbólicos, emocionales, etc, que dejan expuesta la precariedad de los sistemas legales, políticos y urbanos, entre otros. La ciudad se restituye a los soportes básicos que la mantienen y que son puestos a prueba en estos cruciales momentos.

\section{ABSTRACT |}

In addition to all their tragic consequences, earthquakes are a moment of detention, a pause that allows an opening to different symbolic and emotional domains, etc. That leave the weakness of the legal, political and urban systems among others exposed. In The city basic supports of maintainance are reinstated and tested in these crucial moments.

\title{
Los sismos: una historia de fragmentos
}

os sismos se constituyen en un patrimonio Luniversal, tenemos registros de ellos desde los comienzos de nuestra historia. Han sido determinantes no sólo en las formas arquitectónicas que han derivado de la experiencia sísmica acumulada, sino además en la historia misma. Han estado presentes desde los comienzos de la arquitectura, como podemos ver en registros existentes desde Mesopotamia.

A pesar que los terremotos involucran radicalmente a la arquitectura, el conocimiento de ellos ha sido siempre tangente, tal vez por el hecho de que los asociamos más con destrucción que construcción. Es interesante notar que la historia de la arquitectura y otras disciplinas como la arqueología, siempre busca reconstruir a partir de vestigios, de datos, etc. de la manera más veraz posible lo que fue una ciudad, una edificio, un detalle, etc. Esto es posible porque además de la dimensión estrictamente física, surge una dimensión simbólica, que es la que en estos casos se mantiene en pie y da sustento a todas las iniciativas de diverso orden que tenderán ya sea a reconstruir, reparar, levantar o simplemente olvidar lo ocurrido. Son tres los órdenes o dimensiones que comparecen en este caso, una simbólica, una legal y una física.
La dimensión simbólica es la formada por la memoria, los valores, las significaciones, etc., atribuidas a un determinado ámbito urbano o arquitectónico, constituye todo un capital valórico y emocional y suele ser manejado por las instituciones ya sean políticas, religiosas, sociales, etc., que de alguna manera crean y hacen uso del imaginario que se instituye en torno al hecho arquitectónico. Es esta dimensión la que finalmente pesará en la decisión final frente a las labores que proceden en el tiempo posterior a un sismo, será en base a estos valores que se sancionará la duración y tipo de permanencia que le corresponderá a lo que se debe reparar, reconstruir o derribar, y decidirá si su permanencia es en el orden físico o en el orden de la pura memoria, es decir, o permanece como obra o sólo como una fotografía.

Es en esta dimensión en donde suelen aparecer las figuras que por una parte liderarán y manejarán el capital emocional generado por este hecho, una figura que puede ser un sacerdote, un alcalde, o el gobernante del lugar. Esta figura tenderá a tener el rol paternalista o maternalista que dará sustento emocional a los más necesitados. Este rol durante siglos le cupo a la jerarquía religiosa, pues los sismos fueron interpretados como la ira de dios generalmente 
1. Ruinas de Creta, producto de un sismo que habría ocurrido el 1650 a.C.

desatada por el mal comportamiento de hombre, lo que implicaba que un personaje del orden sacerdotal generalmente apareciese como un intercesor ante las fuerzas celestiales para que aplacasen su furia.

«Así, los agentes acreditados de la divinidad podían descifrar el significado y objetivo de estos castigos. Legitimando su privilegiada posición mediadora y levantando una exégesis hegemónica que no admitía relativizaciones, y que estaba destinada a dar un sentido a tanta desolación, reforzando la omnipresente culpabilidad y orientando el terror colectivo hacia estados de purificación expiatoria» (Valenzuela Márquez, 2007).

La dimensión legal está dada por todo el corpus de reglamentaciones que van desde el ámbito meramente político hasta el arquitectónico. Éstas incluyen desde los protocolos de emergencia hasta normas antisísmicas, y ha sido un corpus que ha ido creciendo en el tiempo especialmente después de cada catástrofe, pues son éstas las que más hacen avanzar el sistema.

Por último, la dimensión física de este fenómeno se relaciona con el conjunto de edificios y construcciones que se constituyen como el corpus urbano y arquitectónico de nuestras ciudades, sobre el que operan las otras dos dimensiones, pues es ésta la que directamente sufre los efectos del fenómeno. Ésta puede desaparecer completamente, sin embargo, las otras dos no y es la que nos atañe más directamente, pues es sobre la que la arquitectura actúa directamente.

\section{LOS SISMOS Y LA HISTORIA}

En la medida que indagamos en el tiempo, nos damos cuenta que la presencia de este tipo de catástrofe a lo largo de la historia es muy amplia y variada, sin embargo, aún estando fehacientemente ante nuestros ojos, parecemos no verla, la primera pregunta entonces es el porqué de esta omisión. La respuesta podría surgir del conflicto existente entre la arqueología y la sismología ante la aparición de esta nueva rama que se denomina arqueosismología.

El argumento que esgrimen los sismólogos, es que los arqueólogos e historiadores han sistemáticamente, a lo largo de la historia, excluido la posibilidad de que los sismos sean un agente importante de cambio o transformación histórica, el siguiente párrafo de Arnold Toynbee expresa esto claramente:

\section{«...the breakdowns of civilizations are not} brougth about by the operation of cosmic forces outside human control, we have still to find the true cause of these catastrophes» (Toynbee, 1946).

"One of the perennial infirmities of human beings to ascribe their own failure to forces that are entirely beyond their control» (Toynbee, 1946).

Lo que aquí ocurre es que ante una eventual catástrofe natural no somos nosotros los protagonistas de ellas, y por ello no parece muchas veces en la historia un hecho serio el que el término o decadencia de una civilización se deba a una causa completamente azarosa, impredecible e irracional, como lo pareciera ser un sismo. Los datos y técnicas que la sismología moderna posee nos permiten, sin embargo, ya poder ir determinando científicamente el rol que han tenido los sismos en la historia más claramente.

El resultado de estas indagaciones hasta hoy ha aportado como resultado el entender que el rol de estos eventos ha sido de distinto orden, desde la completa destrucción y desaparición de una cultura hasta ser un hecho imperceptible en el desarrollo de una cultura, en muchos casos, sin embargo, parece haber formado parte de un conjunto de acciones que contribuyeron a la caída o cambio radical de una determinada civilización.

Es interesante notar que a pesar de este ocultamiento de una posible causa catastrófica en importantes cambios en la historia de la humanidad, los vestigios permanecen esparcidos por todo el orbe, como el último y único testimonio de un tiempo detenido, de un tiempo interrumpido, vestigios mudos, pues en la mayor parte de los casos se omite, se silencia o apenas se murmura la razón de tal estado, como si el decir que son producto de un sismo fuera algo vergonzoso, y que hay que ocultar.

Es así como nos encontramos con las ruinas de Creta, producto de un sismo que habría ocurrido el 1650 a.C. y que hizo colapsar a

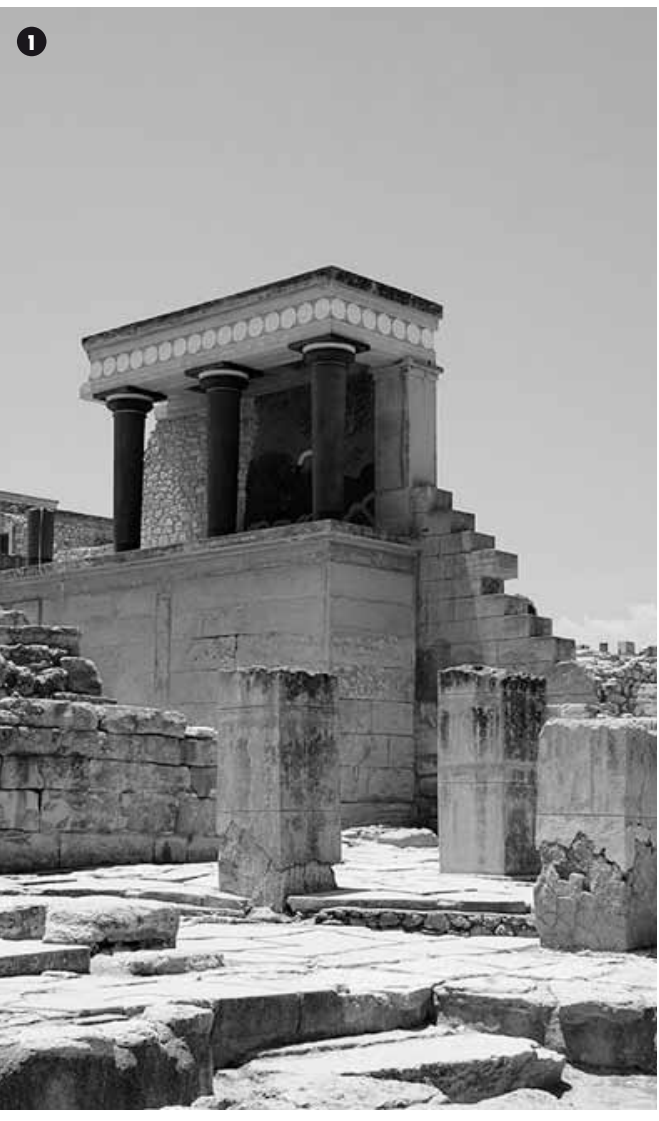

esta potencia marítima del Egeo. Su heredera cultural, la Civilización Micénica, sufriría de un destino similar, ya que un sismo el año 1200 a.C., destruiría completamente la ciudad de Micenas y daría comienzo a lo que se ha denominado como la Edad Oscura Helénica. Troya sucumbiría hacia la misma época por el mismo sismo u otro en época cercana.

Otro vestigio oculto está en la misma Pompeya, si bien conocida por el desastre provocado por la erupción del año 79 d.C., algunos años antes entre el 62 y 63 d.C. se produjo un importante sismo, que provocaría la visita del mismo emperador Nerón para verificar los daños, el cual propuso en la ocasión el traslado de la ciudad, propuesta desoída por sus habitantes con el trágico resultado de la erupción que los sepultaría completamente años más tarde.

En Egipto aún permanecen en el mismo estado en donde cayeron los gigantescos colosos de Ramses II, tanto en Abu Simbel como en el Ramesseum, producto de un sismo que azotó la zona de Luxor y Abu Simbel hacia el año 27 a.C. Los colosos de Mnemón se habrían agrietado por el mismo sismo dando origen a la leyenda a raíz de los sonidos que producía el material al estar agrietado.

"Another wonder of the ancient world, the Lighthouse, or Pharos, at Alexandria, is also thought to have collapsed in an earthquake. As nearly as archaeologists and historians can determine, the structure, first built around 290 BC 


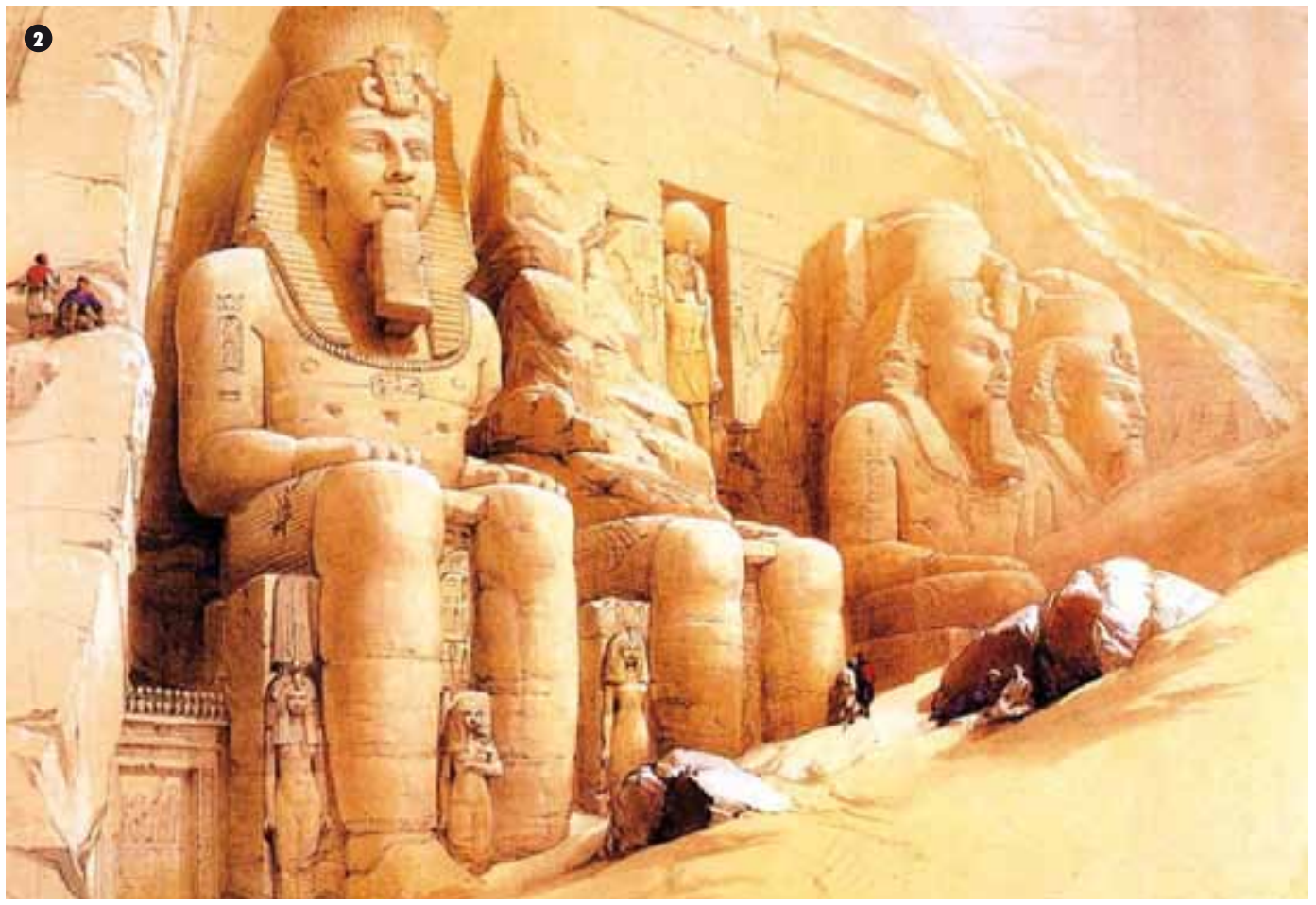

by Ptolemy Soter I and his son, was damaged by several earthquakes during the many centuries of its existence» (Nur, 2008).

Las ruinas del templo de Qalat al Siman en Siria, antigua Iglesia de San Simon el Estilita, aún conserva el tambor de la cúpula que cayó con el sismo ocurrido en Antioquia entre el 526-528 d.C. La cúpula nunca se volvió a erigir.

El Coliseo romano es otro afectado por una de estas catástrofes, pues uno de sus muros exteriores colapsó producto del terremoto de 1349 d.C. Estudios actuales, que incluyen un estudio sísmico con ondas de sonido, descubrieron que la parte que se cayó está sobre un antiguo brazo del río Tíber, el cual ha sido socavado por la parte inferior y produjo la inestabilidad que hizo colapsar el muro.

Más cercanamente en nuestro continente, la caída de Teotihuacán habría sido producto de un sismo ocurrido entre los años 700-750 d.C. Evidencia de ello se encuentra en el desplazamiento de muchas estructuras, junto con la destrucción ritual que sucedió al hecho.
«The Aztecs were fully aware of the occurrence of earthquakes and gave them particular significance in their religious life... The Aztecs believed that the fitth sun, their own, would be destroyed by an earthquake. Such a worldview must have contributed cataclysmic overtones to any major seismic event» (Nur, 2008).

Un hecho similar habría ocurrido en Chichén Itzá, en donde a través del estudio de la caída de las grandes columnatas de sus templos, pudo determinarse como origen de ello a un sismo. En este caso los monumentos fueron restaurados.

\section{EL SISMO Y LA APERTURA A LO IRRACIONAL}

A pesar de que los terremotos involucran radicalmente a la arquitectura, el conocimiento de ellos ha sido siempre tangente, tal vez por el hecho de que se constituye en una apertura a lo irracional.

Las ciudades no son sino el fiel reflejo del orden que hace casi 10.000 años el hombre ha querido plasmar sobre su entorno. La mítica instauración del Cosmos sobre el Caos no es otra cosa que la instauración de un primer orden, el triunfo de lo racional frente a la irracional del caos primigenio, la ciudad como soporte urbano y la arquitectura, se constituyen en el mejor testigo y prueba del esfuerzo humano que ha significado la instauración de este orden. A partir de entonces la evolución y el progreso se han traducido en diversas capas que se han ido agregando al tejido urbano existente otorgándole una densidad y complejidad propia de las ciudades contemporáneas, ocultas bajo esta maraña de estratos superpuestos quedan las huellas de esa primera fundación o instalación ahora completamente olvidada. Es por ello entonces que los sismos implican una abertura a lo irracional, traen a presencia lo que creíamos oculto bajo estas innumerables capas, oculto en las profundidades de la tierra, algo que pensábamos superado, algo de lo que nos creíamos a salvo por el resguardo que el mismo tejido urbano denso nos proporcionaba, el sismo deja en evidencia nuevamente ese caos hesiódico, nos vuelve por un momento a fojas cero, mostrando la vulnerabilidad de nuestras ciudades y construcciones, nos vuelve a una dimensión inicial, primigenia, y esto se produce porque el sismo se constituye en una irrupción de un tiempo distinto en nuestro acontecer histórico diario, es la irrupción violenta y brutal de un tiempo geológico, que se mide en hechos que corresponden más a la edad de la tierra que a la historia humana, es el tiempo al que aluden los mitos, y que creíamos superados formando parte del folclore de las antiguas culturas. Es por esta razón que también nos reconecta nos reinserta en una historia mayor, en un mundo en que vive en un presentismo neurótico, esta detención temporal, se constituye en una oportunidad para resituarnos en un marco histórico mayor, restituye una perspectiva que creíamos perdida.

Esta apertura a lo irracional también puede ser entendida como un «des-ocultamiento», pues el terremoto por otra parte expone lo oculto, lo que hemos querido olvidar, omitir o silenciar como lo muestra lo ocurrido en el terremoto de 1647: «En los días siguientes y subsiguientes se realizaron cientos de confesiones, muchas misas y alrededor de doscientos matrimonios de parejas que tenían relaciones ilícitas, como muestras de arrepentimiento de los pecados y para implorar misericordia divina» (Urrutia, 1993). 
2 y 3. Egipto: colosos de Ramses II, tanto en Abu Simbel como en el Ramesseum, producto de un sismo que azotó la zona de Luxor y Abu Simbel hacia el año 27 a.C.

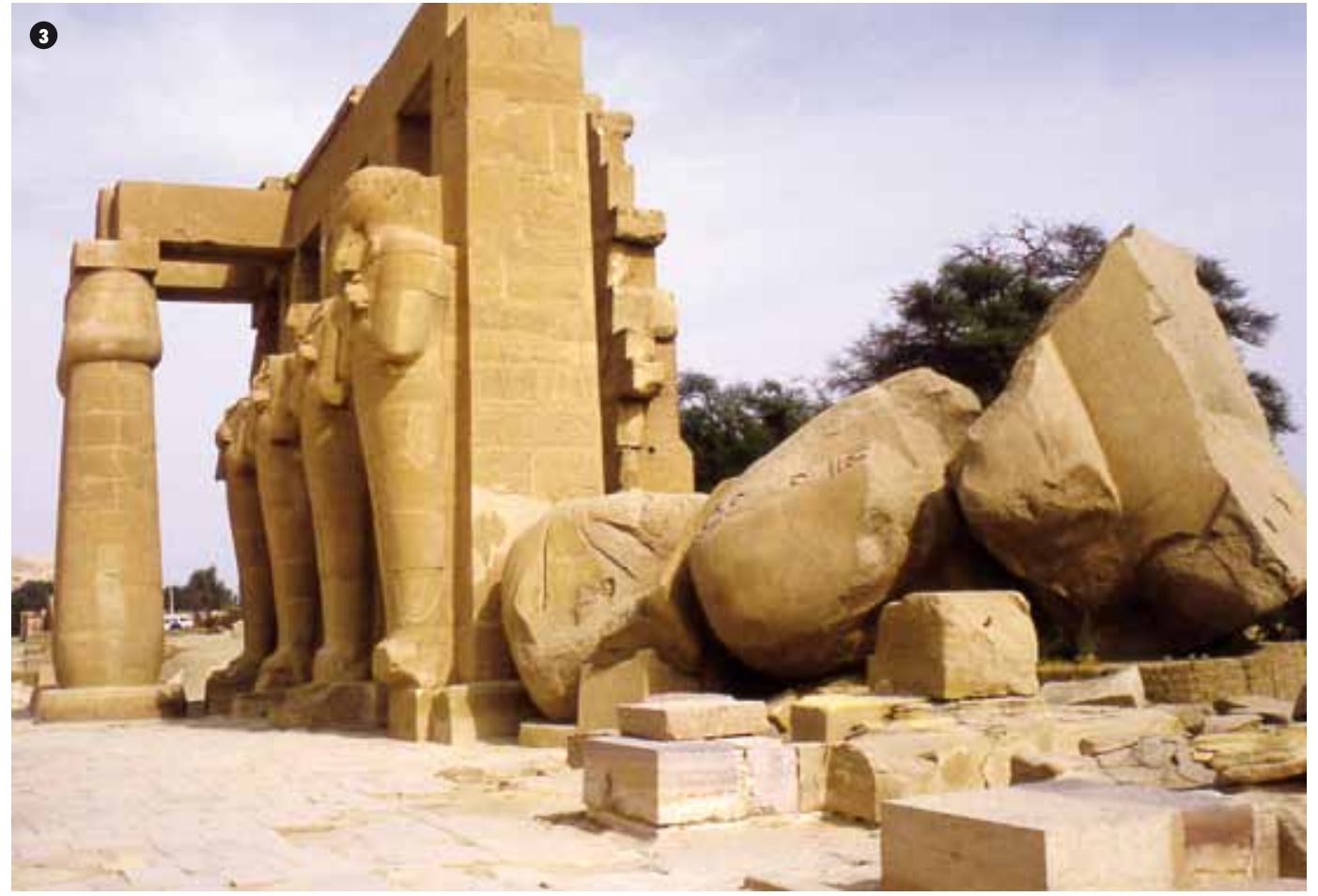

El sismo también deja expuestos los cascos vacíos de un orden que ya no existe, grandes casonas deshabitadas, urbes y pueblos completos que sólo se mantenían por una fachada. El sismo así devela un tejido social que ha desaparecido y que es lo que le da sustento al tejido urbano, de esta manera sólo bota y deja expuesta la última cáscara o fachada de algo que paulatinamente ha ido desapareciendo producto de los cambios sociales que operan aceleradamente de manera que cuando el sismo ocurre sólo rasga la última cortina de un proceso que hacía mucho tiempo había comenzado. Reconstrucción entonces żde qué?, sin un orden social que respalde el orden urbano no parece tener sentido la reconstrucción de «apariencias» de algo completamente inexistente.

\section{EL SISMO Y LA APERTURA A LO FANTÁSTICO}

Esta apertura a lo irracional también implica una apertura a lo fantástico. La irrupción de este tiempo geológico, es la aparición de un tiempo mítico en el tiempo histórico, las antiguas leyendas relacionadas con hecho son reavivadas en estos momentos. Esto tendría su fundamento en el hecho de que la tierra pareciera en estos momentos despertar, se «abren las fauces de la tierra» como generalmente se dice, para permitir escuchar esta voz de la tierra, profunda y enterrada: «Abrióse la tierra por muchas partes y vomitaba negras y pestíferas aguas» (De Rosales, 1877). Es como si la tierra abriera sus entrañas para botar todo un caudal de pestilencias y miasmas infernales. Es interesante además notar que la mayor parte de las palabras con que se hace alusión al sismo hablen de estruendo, rumor, clamor, bramido, crujir, gemido, estrépito, tronar, etc., como si la tierra hablase. Es una voz antigua, profunda que por momentos parece acallar la voz de los hombres.

Los japoneses pensaban que los sismos eran provocados por los movimientos de un pez denominado Namazu, el cual con su sólo movimiento provocaba los sismos: «The folklore on the legendary creature Namazu, a great catfish that lived beneath the earth and supported it» (Nur, 75).

Los Mapuches por su parte atribuían los temblores a la lucha de las Ten-Ten y Kai Kai: of earthquake-prone Japan blamed earthquakes
«El Kai Kai está vinculado como una serpiente de mar o del agua que manda o gobierna el mar. El Kai-Kai Filu es una fuerza exterminadora de la humanidad... EL kai kai filu grito; kai-kai. En ese momento el mar retumbó y se abrieron las vertientes $y$ en ese momento crecieron las aguas y subieron hasta el cielo» ${ }^{[1]}$.

Es a causa del despertar de estas deidades o fuerzas tectónicas, que se hará necesario hacer rogativas y sacrificios para aplacar su ira y restituir el orden. Para aplacar la supuesta ira de Dios como antiguamente se decía, la operación implicaba actuar en diversos dominios simbólicos. Primero se buscaba restaurar el orden mental, anímico, erigir una suerte de andamio espiritual de emergencia que dé sustento a las necesidades espirituales más inmediatas, para ello se invocaban santos, se sacaban reliquias, se instauraban milagros. En el terremoto de 1577 se erigió una ermita para invocar la protección de San Saturnino, Patrono de los temblores y en 1647 se sacó en procesión al Señor de Mayo, producto de un milagro al caer su corona de espinas a su cuello.

«Debemos recordar, en este sentido que todos los eventos luctuosos y catástrofes naturales que vivía Santiago durante la época colonial estaban marcados por rogativos, novenarios y procesiones diversas que clamaban la misericordia de los cielos» (Valenzuela Márquez, 2007).

Aplacar la ira requería igualmente de sacrificios, entre ellos se contaban las autoflagelaciones hasta la petición de la confesión de todos los pecados cometidos, además del restablecimiento del orden moral, sobre todo de las parejas que vivían en estado de pecado.

«El pueblo encontró respuestas espirituales que canalizaban sus deseos y, fundamentalmente buscaban alejar el terror... en ellas participaban personas de todas las clases sociales, especialmente mujeres a las que, vestidas de blanco, descalzas y con los cabellos sueltos

[1] «En Busca de la Tierra Sin Mal Mitos de origen sueños de futuro de los pueblos indios». Memoria de IV Encuentro Taller Ecuménico Latinoamericano de Teología India. Colección Iglesias, pueblos y culturas Nos 60-61. Docutech, Quito, Ecuador. 
recorrían las calles cantando letanías, se le asignaba un papel esencialmente expiatorio, sometiéndolas a rituales mortificantes en lugares centrales y otros espacios igualmente visibles para el público» (Palacios, 2010).

Producto de la casi total destrucción de la mayor parte de la infraestructura urbana en estos grandes sismos, surge ya tempranamente la necesidad de las primeras y rudimentarias construcciones de emergencia, como el Rancho de los Temblores que muchas familias construían en el patio de sus casas alejados de los principales muros de ella.

"Los que antes no se contentaban con palacios y salas muy adornadas, ya tenían a dicha el poder hacer unos pequeños ranchos que componían de la madera y teja de las ruinas, viviendo en las huertas y corrales, ya en toldos, ya en pabellones mal abrigados. La gente permanecía a la intemperie por temor a sucesivos sismos y por el presagio de funestos vaticinios que hacían los vecinos del lugar» (De Rosales, 1877).

Interesante resultar constatar que una vez pasado el tiempo de crisis, en los sucesivos procesos de reconstrucción, ante lo propuesta de algunos vecinos y autoridades de trasladar la ciudad a otros territorios, era la misma iglesia la principal opositora de tal medida, pues eso significaba la desvalorización de los terrenos sobre la cual ella mantenía censos de los cuales obtenía importantes ganancias, que en caso de traslado perdían todo valor.

La restitución del orden a veces pasaba por mayores sacrificios incluso humanos, como se señala en el hecho ocurrido con un niño mapuche con posterioridad al terremoto de 1960

«After this earthquake, a group of Mapuche Indians in the Pacific coastal town of Lago Budi sacrified a five-year-old boy by cutting off his limbs and leaving him for the waves in hope of satisfying the malevolent forces that had caused the destruction» (Nur, 2008).

\section{LO IRRACIONAL COMO EL TEMOR AL OTRO}

Esta detención temporal, que tal vez significaba un retroceso a un origen ya olvidado, hacía surgir nuevamente los temores que acompañaron los primeros tiempos de la Conquista «la élite fragilizada en las bases materiales y mentales que sustentaban el control social colonial, reencontró el miedo al otro dominado. Sin contar tomar en cuenta que indígenas y africanos habían sido los grupos más diezmados por la catástrofe» (Valenzuela Márquez, 2007). El temor principal era a la insurrección indígena, como correlato casi lógico en esta vuelta a lo salvaje, el indígena representaba lo irracional de alguna manera que había sido expulsado del cosmos urbano. Recordemos que en los primeros siglos de la Colonia los indígenas formaban el estrato más bajo de la sociedad colonial «los indios mostraban la disolución de su antigua cultura y la aniquilación de sus miembros, sumidos en la miseria, la promiscuidad, las enfermedades y el vivió» (De Ramón, 2000). Por ello habitaban principalmente en los arrabales en la periferia de la ciudad o en poblados cercanos.

Ante la situación de fragilidad y desamparo en que se encontraba la sociedad de la época, este miedo no era sino casi la consecuencia natural de un acto irracional como lo era un sismo para ellos. Es interesante notar, sin embargo, que el temor experimentado en los primeros sismos de tiempos de la Colonia por este «otro indígena» va a permanecer en el tiempo, sólo que cambiará de sujeto, como es posible verificar en lo sucedido en el sismo de 1822. En este caso el «otro» causante de esta tragedia resultaba para muchos ser el "extranjero»: «...algunos sacerdotes, predicando entre las ruinas, comenzaron a preparar una representación popular en la que le exigían al gobierno la inmediata expulsión de todos los ingleses y norteamericanos, los 'herejes' como eran llamados, ya que su residencia en Chile era la causa, según decían, de la corrupción y el mal manejo de las autoridades, y sus sacrílegos comportamientos el motivo que tuvo Dios para castigar al país con tal calamidad» (Palacios, 2010). Los ingleses y norteamericanos por ser principalmente extranjeros y protestantes eran considerados la causa de tal fenómeno.

\section{DESAMPARO URBANO Y ORFANDAD POLÍTICA}

"Acudían a las iglesias y hallábanlas caídas, los retablos deshechos, las imágenes por los suelos, y lo que más lastima, las sagradas custodias del Señor abolladas y las divinas formas revueltas en el polvo y las astillas. Esto causaba mayor llanto y obligaba a todos a dar más dolorosos gemidos, viendo que no tenía a donde hallar descanso su pena ni donde pedir misericordia su culpa» (De Rosales, 1877).

El desamparo en el que queda la población expuesta con posterioridad a un sismo de gran magnitud y destrucción, tiene como subproducto inmediato el surgimiento de un sentimiento de "orfandad», una orfandad que opera en todos los niveles.

«En medio de este tiempo apocalíptico, surge un verdadero sentimiento de orfandad antiguamente religiosa, y ahora política el que se experimentaba» (Valenzuela Márquez, 2007).

Esto se produce porque una catástrofe de esta magnitud implica un corte, una detención, un quiebre en la historia, que interrumpe la historia misma, y con ello su continuidad. Pero no es solamente la historia la que se detiene, con ella se interrumpen la linealidad de los procesos, las genealogías, los vínculos que una sociedad ha establecido.

En el nivel simbólico esta orfandad se produce primero a nivel social por el rompimiento del vínculo, si lo pudiésemos denominar así, paternal con las instituciones que nos «amparan» y nos resguardan. Llámese en este caso las instituciones del Estado, ya sea por su desaparición o por la ineficacia en asumir su rol (pienso que más bien es un extravío, ante la falibilidad del rol paternal por parte del Estado en las sociedades capitalistas contemporáneas), y en el nivel íntimo por la pérdida de nuestros seres queridos, conllevando con ella a la pérdida de la unidad familiar.

En el nivel legal, la orfandad se produce como consecuencia de la ausencia de la figura simbólica que detenta el poder y por la detención misma del «estado legal» que ocurre en estos casos, por ello la catástrofe constituye 
un estado de excepción. Pero también como consecuencia directa de la pérdida del soporte físico.

El ámbito físico es en donde se hace más aparente esta orfandad, pues una catástrofe como ésta primero destruye o debilita el soporte físico urbano de la ciudad, desaparecen las calles, se caen los templos y edificios institucionales, el soporte físico que le da una figura a la ciudad desaparece, dejando al habitante en una completa orfandad urbana. Si a eso agregamos la pérdida del hogar, estamos con ello rompiendo finalmente con los vínculos ancestrales que nos legitimaban dentro de una determinada historia familiar.

Es quizás la pérdida de esta dimensión física principalmente la que nos retorna al origen mismo de la ciudad, pues la única dimensión que pasa a sostener todo este constructo civil es la simbólica, es decir, la ciudad se vuelve Polis como originariamente se entendió, se pierde la dimensión de la Urbis y sólo queda la dimensión de la ciudad como ente político, Polis.

Recordemos que la ciudad antes que ser una entidad física fue una entidad legal. Esta entidad política se plasma en una entidad física que nos da resguardo a casi todo. La trama urbana de la ciudad ha sido un resguardo simbólico para sus habitantes, por ello durante mucho tiempo todo aquello que era considerado salvaje o natural, como los indios estaban fuera de ella. La restitución de este orden o dimensión física es necesaria entonces ya sea para consolidar y darle continuismo a un orden simbólico o bien para generar uno completamente nuevo.

Este desnudamiento producto de la desaparición del orden físico tiene otras consecuencias además. En este caso preciso lo que aparece expuesto es la pérdida de un determinado tejido social que ya no existe. La unidad morfológica que se forió durante siglos estuvo amparada por un determinado tipo de sociedad que servía de sostén a este rostro arquitectónico y las fachadas caídas sólo terminaron por mostrar la completa ausencia o vaciedad de tales vínculos. En aquella sociedad, el valor lo otorgaba la comunidad como un todo y es esa comunidad la que ya no parece existir, ya sea producto de las migración de las generaciones jóvenes, del envejecimiento creciente de nuestra población o de las nuevas costumbres que impone nuestra actual sociedad de consumo.

\section{El problema entonces se centra en que el} rescate de la vivienda en tanto unidad, del fragmento urbano, no parece tener ningún sentido, salvo en la dimensión del museo. La primera pregunta entonces es de qué manera damos una respuesta global a este desafío, de qué manera logramos reconstruir o generar un nuevo tejido social que permita generar nuevos vínculos acorde a los nuevos tiempos, y la segunda es quién será el agente ejecutor que sea capaz de llevar todo esto a cabo, que sea capaz de dar no sólo una respuesta de «emergencia» sino que permita volver a vincular estas tres dimensiones respondiendo a cada una de ellas pero de una manera conjunta, żes el arquitecto, el economista, el alcalde, la empresa privada? Alguien tiene que asumir este rol, de ello depende el éxito de restituirle a la Polis su calidad Urbis.

\section{BIBLIOGRAFÍA}

De Ramón, Armando. Santiago de Chile: 1541 1991: Historia de una sociedad urbana. Editorial Sudamericana, Santiago, 2000.

De Rosales, Diego R.P. Historia General Del Reyno De Chile. Imprenta Del Mercurio, Valparaíso, 1877.

Nur, Amos. Apocalypse. Earthquakes, archeology and the Wrath of God. Princeton University Press, Princeton and Oxford, 2008.

Palacios Roa, Alfredo. "Cotidianidad y religiosidad ante la catástrofe: el terremoto de 1822». Historia de la Iglesia en Chile. Tomo II. Cap. XII. Sánchez, Marcial (Director). Editorial Universitaria, 2010.

Toybbee, Arnold J. A Study of History. Vol. I. Oxford University Press, 1987.

Urrutia de Hazbun, Rosa; Lanza Lazcano, Carlos. Catástrofes en Chile 1541-1992. Santiago, Editorial La Noria, 1993.

Valenzuela Márquez, Jaime (Editor). Historias urbanas. Homenaje a Armando de Ramón. Santiago, Ediciones Universidad Católica de Chile, 2007. 